\title{
A EXPERIÊNCIA DA APRENDIZAGEM MEDIADA NO DESENVOLVIMENTO DA METACOGNIÇÃO ATRAVÉS DOS CICLOS DE LEITURA MAISPAIC
}

\author{
CRIGINA CIBELLE PEREIRA (UERN-PFERROS) ${ }^{1}$ \\ JOELMA UCHOA PINHEIRO (UERN-PFERROS) ${ }^{2}$ \\ JAQUELINE DE JESUS BEZERRA (UERN- PFERROS) ${ }^{3}$
}

\begin{abstract}
RESUMO: Este artigo discute sobre o espaço da literatura no ensino fundamental por meio da Experiência da Aprendizagem Mediada nos Ciclos de Leitura do Programa de Aprendizagem na Idade Certa (MAISPAIC), no eixo de Literatura e Formação do leitor. Objetivamos apresentar uma discussão acerca da atuação do professor como mediador da aprendizagem, no desafio de despertar nos alunos o gosto pela leitura de deleite e o desenvolvimento da autonomia estudantil. Analisamos os Ciclos de Leitura MAISPAIC sob três perspectivas teóricas que fundamentam a proposta do Programa. Para a mediação da aprendizagem, tomamos as concepções de Vygotsky (1991), sobre o sociointeracionismo pela linguagem com vistas ao desenvolvimento cognitivo e de Feuerstein (1991), bem como demais estudiosos, por discorrerem sobre a Experiência da Aprendizagem Mediada como impulsionadora da modificabilidade cognitiva estrutural; na perspectiva dialógica da interação entre leitor, texto e autor, trazemos o olhar de Bakhtin (1997, 2016), integrando-o às ideias de Solé (1998) e Cosson (2014), que apontam a leitura compartilhada como um momento interacional da linguagem em função do letramento literário dos alunos; para compreender a visão de educação impressa nessa proposta, buscamos a partir de Freire(1987), analisar as relações de proximidade entre as experiências do Círculo de Cultura e a vivência dos Ciclos de Leitura no cotidiano escolar. A pesquisa adota uma abordagem qualitativa de natureza aplicada, englobando o estudo bibliográfico sobre a teoria da aprendizagem mediada, a análise documental do material orientador do MAISPAIC e as experiências vivenciadas nas formações de professores ofertadas pelo programa. Os resultados apontam os Ciclos de Leitura como uma experiência de mediação da aprendizagem que tem impulsionado os docentes a abordarem novas estratégias para o trabalho de compreensão textual e influenciado os alunos no aprendizado do deleite literário para desenvolvimento da metacognição e formação de leitores protagonistas.
\end{abstract}

PALAVRAS-CHAVE: Leitura literária. Professor-mediador. Ciclos de leitura. Metacognição. Leitor protagonista.

ABSTRACT: This article discusses the space of literature in elementary school through the Mediated Learning Experience in the Reading Cycles of the Right Age Learning Program(MAISPAIC), in the axis of Literature and Reader Formation. We aim to present a discussion about the teacher's role as a mediator of learning, in the challenge of arousing in students the taste for reading delight and the development of student autonomy. We analyze the MAISPAIC Reading Cycles from three theoretical perspectives that underlie the Program proposal. For the mediation of learning, we take Vygotsky's (1991) conceptions of socio-interactionism by language for cognitive development and Feuerstein (1991), as well as other scholars, for discussing the Mediated Learning Experience as a driver of cognitive modifiability structural; From the dialogical perspective of the interaction between reader, text and author, we bring Bakhtin's $(1997,2016)$ perspective, integrating it with the ideas of Solé (1998) and Cosson (2014), who point to shared reading as an interactional moment of language according to the students literary literacy; To understand the vision of education printed in this proposal, we sought from Freire (1987) to analyze the close relations between the experiences of

\footnotetext{
1 Doutora e mestra em Estudos da Linguagem pela Universidade Federal do Rio Grande do Norte, criginacibelle@uern.br

${ }^{2}$ Mestranda do Programa de Pós-graduação em Ensino pela Universidade Estadual do Rio Grande do Norte, joelmauchoapinheiro@gmail.com

${ }^{3}$ Mestra em Letras pela Universidade Federal de Campina Grande, Campus Cajazeiras e doutoranda em Letras na Universidade do Estado do Rio Grande do Norte, linnebezerra@gmail.com

Revista Trama | Volume 16 | Número 37 | Ano 2020 | p. 100-111 | e-ISSN 1981-4674
} 


\section{$=$ TRAMA $=$}

the circle of culture and the experience of reading cycles in school daily life. The research adopts a qualitative approach of applied nature, encompassing the bibliographical study on the theory of mediated learning, the documentary analysis of the MAISPAIC guiding material and the experiences lived in the teacher training offered by the program. The results point the Reading Cycles as a learning mediation experience that has motivated the teachers to approach new strategies for the textual comprehension work and influenced the students in the learning of the literary delight to develop the metacognition and formation of protagonist readers.

KEYWORDS: Literary reading. Mediator teacher. Reading cycles. Metacognition. Protagonist reader

\section{INTRODUÇÃO}

O aprendizado da leitura literária na escola tem gerado inúmeras discussões a respeito da sua funcionalidade e das formas como os textos vêm sendo abordados em sala de aula, cuja realidade aponta para um certo descaso e desinteresse pela leitura por boa parte dos alunos. Desta forma, temo-nos perguntado sobre as experiências que a escola tem proporcionado aos estudantes na apreciação e compartilhamento da leitura literária. Estariam as atividades de compreensão textual promovendo o intercâmbio cognitivo entre autor, obra e leitor? O texto literário encontra espaço na sala de aula para discussão e construção de sentidos ou mantémse fadado a fins exclusivamente didáticos? Tomando essas indagações como norteadoras desse estudo, dispomo-nos a discutir sobre o espaço da literatura no ensino fundamental por meio da Experiência da Aprendizagem Mediada nos Ciclos de Leitura do Programa de Aprendizagem na Idade Certa (MAISPAIC), no eixo de Literatura e Formação do Leitor.

Partimos dos Ciclos de Leitura do MAISPAIC para investigar as experiências dialógicas tecidas no cotidiano escolar, entre a obra literária e os alunos, mediadas pelo professor. Entendendo a vivência dessa atividade como uma extensão dos momentos formativos do Programa, procuramos compreender as conexões entre as teorias ali discutidas e a prática exercida pelos docentes. Sabendo que, ao possibilitarmos aos jovens leitores uma visão de mundo para além do contexto local, estamos fazendo uso da metacognição, promovendo um exercício contínuo do pensar sobre o pensar, para que os alunos possam encontrar os seus próprios modos de refletir sobre a vida.

Nossas reflexões buscam compreender o percurso metodológico utilizado pelos docentes para despertar nos alunos o gosto pela leitura de deleite e o desenvolvimento da autonomia estudantil, estimulando a vivência da cultura do pensar, por meio da apreciação de obras literárias e do compartilhamento das suas significações entre os alunos leitores. Para isso, tecemos uma discussão acerca do conceito de mediação, interligando-o ao ensino da leitura literária, apresentando a experiência do Ciclo de Leitura como um caminho possível para a realização de atividades próprias ao desenvolvimento da metacognição dos alunos e à formação de leitores protagonistas.

A metodologia adotada nesse artigo envolve o estudo bibliográfico sobre a teoria da aprendizagem mediada, a análise documental das orientações do Programa MAISPAIC para o Eixo de Literatura e Formação do Leitor, e as experiências vivenciadas com a mediação da leitura literária durante atuação como técnica responsável pelo acompanhamento das formações dos professores. Adotamos uma abordagem qualitativa de natureza aplicada, cujo intuito é analisar as relações tecidas entre o material orientador das formações para os Ciclos de Leitura nas escolas e o fazer pedagógico docente, no que diz respeito tanto à atuação do professor como mediador, quanto à socialização do acervo literário do MAISPAIC, disponibilizado às escolas para formação inicial de leitores. 


\section{$=$ TRAMA $=$}

Para melhor compreendermos o trabalho com a leitura literária na escola, no tocante à Experiência da Aprendizagem Mediada, doravante (EAM), partimos das perspectivas de Vygotsky (1991), na formulação do conceito de aprendizagem social, mediada por meio da linguagem e da interação social, com vistas ao desenvolvimento cognitivo. Buscamos também apoio em Feuerstein (1991), ao discorrer sobre a EAM como um caminho que conduz à modificabilidade cognitiva estrutural. Ambos os autores admitem ser por meio do processo mediacional que ocorre a ampliação das competências cognitivas dos alunos.

Ao trazermos essa perspectiva para o trabalho com literatura na escola, estamos enfatizando o valor da EAM na proposição de estratégias que possam gerar significados para o aprendizado da leitura e desenvolver habilidades de compreensão textual. O professor, ao atuar como mediador de leitura, deve promover momentos de partilha literária e possibilitar o progressivo desenvolvimento da autonomia dos alunos, por meio de uma educação interativa e intencional, oferecendo estímulos que contribuam para o aperfeiçoamento cognitivo dos estudantes.

Compreendemos a mediação de leitura como um processo dialógico, de partilha literária para construção dos significados de uma obra, na linha do que discute Bakhtin (1997), para quem "o acontecimento da vida do texto, isto é, sua verdadeira essência, sempre se desenvolve na fronteira de duas consciências, de dois sujeitos."(BAKHTIN, 2016, p. 76). Ou seja, o texto é entendido como um enunciado repleto de muitas vozes e cuja intenção de produção e execução só se concretiza na interação com o outro. Nesse caso, a obra literária constitui-se de um texto destinado a um leitor, que ao entrar em contato com a leitura, torna-se participante ativo na interação entre autor-obra-leitor, assumindo uma atitude responsiva na construção de sentidos e significados atribuídos aos enunciados. Nesse momento, ocorre o que Bakhtin (2016) descreve como um encontro de dois textos- do texto pronto e do texto a ser criado; o encontro de dois sujeitos, o autor escritor e o leitor autor.

Acrescentamos à proposta de Bakhtin $(1997 ; 2016)$ as considerações de Solé (1998) e de Cosson (2014), a respeito da experiência da leitura compartilhada, evidenciando a relevância do papel do docente na formação de leitores competentes. O professor, ao pautarse no propósito do letramento literário, possibilita aos estudantes a construção de sentidos despertados pelo ato da leitura individual de determinada obra e pelo compartilhamento das suas experiências entre os colegas.

Assim, conforme destaca Cosson (2014), a vivência com a literatura deve envolver a leitura como um ato solitário, realizada individualmente, e a leitura como um ato solidário, praticada coletivamente pela partilha das significações extraídas da obra lida pelos estudantes. Nesse seguimento, os Ciclos de Leitura encontram-se também fundamentados pelo ideal do Círculo de Cultura proposto por Freire (1987), numa visão de educação democrática e libertadora, comprometida com temáticas de interesse dos estudantes, para discussão e ampliação da própria visão de mundo, na tomada de consciência sobre a realidade.

Ao adotarmos essa visão, assumimos a concepção de leitura como uma prática social, na qual ler é interagir com o texto. Nesse processo, há de se considerar conhecimentos prévios do leitor a respeito do conteúdo da obra, os sentidos por ele construídos a partir da leitura do texto e o processo de interação entre texto e leitores, numa atividade de compartilhamento de experiências para além da cognição.

O professor assume o papel de mediador na tarefa de estimular a cultura do pensar, contribuindo para a formação do leitor protagonista, cujas habilidades cognitivas de percepção, atenção, assimilação, comparação, memória, entre outras, vão além do significado literal das palavras do texto. Conforme enfatiza Bakhtin, (2016, p.68): "A língua como sistema tem uma 


\section{$=$ TRAMA $=$}

imensa reserva de recursos puramente linguísticos para exprimir o direcionamento formal: recursos lexicais, morfológicos, sintáticos. Entretanto, eles só atingem o direcionamento real na totalidade de um enunciado concreto." Ou seja, as palavras só adquirem significado real, quando inseridas dentro de um contexto comunicativo, por isso a importância do mediador propiciar o intercâmbio dialógico entre o autor, o texto e os alunos leitores, para que estes adentrem no contexto da obra e de lá, possam atribuir suas próprias significações para o texto.

Nesse artigo, tratamos ainda da conceituação do termo "Metacognição", nas considerações trazidas por Neves (2007), ao compreender essa atividade como a consciência do modo pelo qual o conhecimento é adquirido, tornando possível que os próprios indivíduos gerenciem esse processo, utilizando estratégias para aprendizagem e resolução de problemas cotidianos. Desta forma, a metacognição encontra-se relacionada aos modos como cada estudante reflete a respeito de um problema, situação ou conteúdo escolar que the é apresentado como novo, exercitando a organização do pensamento e buscando estratégias para sua resolução.

Ao intencionar o desenvolvimento metacognitivo dos alunos, o professor mediador deve propiciar-Ihes o diálogo aberto com a obra literária, visando a ampliação dos seus conhecimentos enciclopédicos e a tomada de posicionamento diante do texto, assumindo assim uma atitude responsiva de interlocutores ativos. Segundo Bakthin (1997), essa atitude torna-os capazes de concordar ou discordar, totalmente ou parcialmente, refletindo e reavaliando os conceitos trazidos pela leitura.

\section{A EXPERIÊNCIA DA APRENDIZAGEM MEDIADA NA FORMAÇÃO DO LEITOR E NO DESENVOLVIMENTO DA METACOGNIÇÃO}

Pretendemos discutir, nesta seção, a teoria da mediação da aprendizagem à luz de Vygotsky (1991) e Feurstein (1991), apresentando os aspectos relevantes do processo mediacional para a modificação da estrutura cognitiva dos alunos em relação à aquisição e aperfeiçoamento das competências para domínio da leitura. Partimos da compreensão dos autores sobre o aprendizado como algo social, fruto da interação do indivíduo com o seu meio. Entretanto, para haver o amadurecimento do processo interpessoal para o intrapessoal, Vigotsky (1991) destaca a necessidade do uso de instrumentos e símbolos como meios auxiliares no processo de internalização de conceitos, que levam ao desenvolvimento das funções psicológicas superiores.

Feuerstein (1991), ao posicionar-se de modo semelhante, aponta a aprendizagem mediada como um fator preponderante para o desenvolvimento cognitivo. Para este autor, há duas modalidades de aprendizagem, através da abordagem direta e como uma abordagem mediada; a primeira ocorre incidentalmente, resultado direto da interação do indivíduo com o seu meio, e de acordo com o autor, não é suficiente para efetivação da aprendizagem. A outra modalidade desenvolve-se pela interferência do mediador que, ao observar as experiências e interesses dos sujeitos diante dos estímulos oferecidos pelo meio em que vivem, aproveita-se desses conhecimentos para promover novas aprendizagens, interagindo com cada indivíduo de forma intencional.

Desse modo, a EAM trazida por Feuerstein (1991) compreende um caminho a ser percorrido pelo mediador que, guiado por intenções de promover aprendizagem, cultura e envolvimento emocional, seleciona e organiza o mundo de estímulos propícios a cada etapa/série escolar, selecionando aqueles mais apropriados ao desenvolvimento da aprendizagem e ao crescimento intelectual dos estudantes. Assim, complementa Silva et al (2011, p. 17): 


\section{$=$ TRAMA $=$}

[...] a mediação conceitua-se como uma metodologia pela qual se desenvolve uma influência mútua entre um sujeito com funções cognitivas deficientes ou insuficientes com o outro sujeito que já seja dono de um saber experimentado com visão intencionada para provocar transformações ou aprimoramento de tais funções cognitivas, de maneira que essa mediação seja compreendida como decorrência ajustada da exposição direta do sujeito com o meio e à experiência de aprendizagem mediada, que tem seu planejamento e avaliação desenvolvidos pelo mediador, que deve estar atento às necessidades do mediado, considerando sua cultura, que é o alicerce para a existência de significados para os estímulos propostos.

As teorias de Vygotsky (1991) e Feuerstein (1991) comungam dos mesmos princípios, ao associarem o desenvolvimento e aperfeiçoamento cognitivo do ser humano ao seu contexto histórico e social. No âmbito escolar, os estímulos retirados do meio cultural dos estudantes são utilizados pelo mediador em função de um propósito de aprendizagem predefinido, tendo em vista o aperfeiçoamento das estruturas cognitivas do ser em desenvolvimento.

Nesse trabalho de mediação de leitura, há um envolvimento do mediador nas ações de promoção do livro, na partilha literária e na construção de sentidos para o texto, além do acompanhamento contínuo no processo de evolução da competência leitora de cada estudante, atuando de forma pontual para a superação das limitações cognitivas. Vale ressaltar que o trabalho com a leitura não se limita à mera decodificação da escrita, devendo proporcionar às crianças e jovens, experiências que agucem a sua percepção de mundo e amadureçam o seu intelecto, fazendo-os compreender as relações existentes entre a leitura literária e a sociedade da qual fazem parte, procurando adequar-se, modificar-se ou conflitarse com as verdades ou imposições culturais do seu cotidiano.

Para que o leitor vá adquirindo essa habilidade de compreensão do mundo ao seu redor, faz-se necessário apresentar a literatura como algo que desperte o interesse, a curiosidade e o encantamento, servindo-lhe como uma espécie de "portal mágico" que Ihe permita transitar por diferentes espaços, histórias, relações, sentimentos, contradições, possibilitando-Ihe retirar do universo ficcional significações e aprendizados para a sua realidade cotidiana.

Sendo assim, a vivência da leitura de deleite deve funcionar na escola como uma espécie de motivação para potencialização do aprender. O professor deve fazer do ato da leitura um momento de deleite literário, mantendo-se atento aos temas de interesse dos alunos, bem como às suas reais necessidades cognitivas. Podendo, assim, unir o propósito da leitura literária prazerosa ao desenvolvimento das funções cognitivas dos estudantes.

No entanto, muitas vezes, o que percebemos no cotidiano escolar é a vivência da leitura como algo obrigatório, enfadonho, limitado ao trabalho com fichas de leitura, ou sequências de perguntas e respostas relativas ao texto, o que nem sempre contribui para o processo de emancipação do leitor, segundo afirma Cosson (2014, p. 22):

No ensino fundamental, predominam as interpretações trazidas pelo livro didático, usualmente feitas a partir de textos incompletos, e as atividades extraclasses, constituídas de resumos dos textos, fichas de leitura e debates em sala de aula, cujo objetivo maior é recontar a história lida ou dizer o poema com suas próprias palavras.[...] As fichas de leitura, condenadas por cercear a criatividade ou podar o prazer da leitura, são no geral voltadas para a identificação ou classificação de dados, servindo de simples confirmação da leitura feita.

Por essa razão, é que também destacamos o posicionamento de Zilberman (1994), para quem a obra literária em sala de aula não pode ser considerada um instrumento de normas, 


\section{$=$ TRAMA $=$}

nem linguísticas, nem comportamentais, devendo assumir o seu destino inquiridor e cognitivo. Como percebemos, o emprego do livro de literatura na escola deve servir para fazer pensar, indagar, levantar questionamentos e ampliar os olhares para o mundo, despertando emoções e prazer pelo ato de ler, tendo como consequência, e não como único objetivo, a evolução cognitiva dos alunos. Do contrário, se sua utilização vem servir estritamente para fins didáticos e pedagógicos, a literatura se transforma em instrumento de ensino, que ao invés de despertar o interesse dos alunos, causa repúdio e aversão, distanciando-os cada vez mais da experiência fruitiva com o texto.

Dessa maneira, cabe à escola, enquanto espaço de vivência social e multicultural, e aos professores na atuação como mediadores, proporcionarem momentos de deleite do texto literário, permitindo aos alunos o mergulho no contexto da obra, em busca de significados despertados nos leitores para reflexão coletiva. É o que Bakhtin (2016) denomina de "réplica do diálogo": o leitor ao entrar em contato com a obra literária, sofre uma influência educativa, que por sua vez, instiga-o a assumir uma compreensão responsiva do texto, dialogando com os enunciados, tomando posicionamentos diante do conteúdo da obra e expondo seus questionamentos.

Conforme destaca Bakhtin (2016, p. 57), "todo enunciado é pleno de ecos e ressonâncias de outros enunciados com os quais está ligado pela identidade da esfera da comunicação". Ou seja, a expressão dos enunciados construídos a partir dos sentidos e significações retirados de uma obra lida constituem-se como respostas ao diálogo fundado entre o autor, o texto e o leitor. Dessa interação, o leitor produz novos enunciados, também constituídos de ecos discursivos de outros falantes ou escritores, que ao serem incorporados na sua fala, passam a demonstrar a sua visão de mundo, que nada mais é do que o resultado das suas experiências de interação social.

Nesse contexto dialógico entre autor, obra e leitor, muito se discute acerca da importância da leitura e da forma como o texto literário vem sendo abordado na escola, cuja responsabilidade, frente ao desafio de formar alunos leitores, torna-se cada vez mais evidente. Dessa forma, trazemos a vivência dos Ciclos de Leitura MAISPAIC, como exemplo do trabalho com a leitura literária na escola para desenvolvimento da metacognição. A essência dessa metodologia está no fortalecimento do gosto pela leitura, tomada como um ato individual e coletivo, tendo em vista a formação de leitores protagonistas.

\section{A EXPERIÊNCIA DA APRENDIZAGEM MEDIADA NOS CICLOS DE LEITURA MAISPAIC PARA O DESENVOLVIMENTO METACOGNITIVO DOS ESTUDANTES}

A Secretaria da Educação do Estado do Ceará desenvolveu o Programa de Aprendizagem na Idade Certa - MAISPAIC a partir do pressuposto de que a prática escolar de alfabetização não é suficiente para formar o leitor letrado, ou seja, crítico, criativo, pensante, com competência para interpretar os mais diversos tipos de textos. E também pela necessidade de democratizar o acesso ao livro às crianças e adolescentes, contribuindo no domínio de habilidades e competências da leitura e da escrita. Trata-se, portanto, de um programa de aprimoramento das ações de qualificação do processo de alfabetização e de formação continuada de professores.

Ao longo do tempo, o Programa MAISPAIC foi se modificando e ampliando seu campo de atuação. Surgiu, inicialmente, no ano de 2007, sob a denominação de PAIC (Programa de Alfabetização na Idade Certa), tendo como objetivo atuar no combate ao analfabetismo, dando suporte técnico-pedagógico aos municípios cearenses, para tornar possível a alfabetização de todas crianças do Ceará até os sete anos de idade e formar leitores fluentes, oferecendo 


\section{$=$ TRAMA $=$}

formações pedagógicas aos professores, da educação infantil ao $2^{\circ}$ ano do Ensino Fundamental. Em 2011, seu atendimento se estende até o $5^{\circ}$ ano, com o propósito de melhorar os resultados de aprendizagens dos alunos, recebendo assim a denominação de PAIC MAIS. Posteriormente, no ano de 2015, foi instituído o Programa MAISPAIC como uma política de complementação do PAIC, para fortalecimento da aprendizagem dos estudantes no ensino Fundamental II.

Considerando as trajetórias do MAISPAIC nesses treze anos de atuação, podemos afirmar que o programa constitui-se como uma política pública de fortalecimento da aprendizagem dos alunos em todas as tapas do Ensino Fundamental. Para atender a demanda dos municípios, atualmente, encontra-se estruturado em diversos eixos de atuação 4 , distribuídos da seguinte forma: Eixo de Gestão, Eixo de Educação Infantil, Eixo do Ensino Fundamental I, Eixo do Ensino Fundamental II, Eixo de Avaliação Externa e Eixo de Literatura e Formação do Leitor.

O Eixo de Literatura e Formação do Leitor tem como meta desenvolver uma política de formação de leitores envolvendo professores e alunos. Visa ainda democratizar o acesso ao livro e à leitura por meio da aquisição e dinamização de acervos literários para as escolas, incentivando o gosto pela leitura e pela escrita, no entendimento de que o texto literário é um instrumento de aprendizagem e um alimento para o crescimento humano. A experiência que buscamos partilhar refere-se à implementação dessa metodologia dentro das formações do MAISPAIC, destinada aos professores de Língua Portuguesa, com vistas a subsidiar a prática docente para a atuação mediadora nos Ciclos de Leitura realizados nas escolas.

Os Ciclos de Leitura MAISPAIC são ações de compartilhamento da fruição literária, promovidas no cotidiano escolar, cujo intuito é estimular os alunos no despertar do gosto pela leitura. Essas ações são direcionadas aos professores de Língua Portuguesa, que após receberem orientações, durante o processo formativo do Programa, assumem a função de mediadores, comprometendo-se com a oralização dos textos na partilha literária e com a mediação nas discussões dos alunos diante da obra apresentada. Nessa vivência, o professor atua como um mediador da leitura e organiza momentos em sala ou em outros espaços da escola, propícios à realização do Ciclo de Leitura, cuja finalidade é despertar o gosto pela leitura e formar leitores protagonistas.

Para isso, consideramos duas etapas como cruciais na concretização da experiência da Aprendizagem mediada: o momento de planejamento, no qual o professor deve selecionar a obra, pensando em textos que sirvam aos interesse dos alunos, exercitar a leitura em voz alta e anotar os possíveis questionamentos a serem levantados diante do texto lido; e a vivência da partilha literária, que deve ter, como objetivos, oportunizar o contato dos alunos com o texto escrito e criar momentos de interação em círculo para discussão após a leitura da obra. As ações desenvolvidas nessa experiência vão ao encontro do que definiu Feuerstein (1991 apud Silva et al, 2011, p.26), como parâmetros universais de mediação, tidos como interligados e primordiais ao mediador:

[...] intencionalidade do mediador e reciprocidade do mediado, por meio da formação de vínculos entre ambos; significado, quando o mediador incita a construção de significados, por meio de valores, atitudes culturais, laços sociais e outros elementos que desenvolvam no mediado um processo de construção de

\footnotetext{
4 A página do Programa MAISPAIC traz ao conhecimento público as informações relativas às ações desenvolvidas em cada eixo de ensino, obtidas.pelo seguinte endereço eletrônico: https://paic.seduc.ce.gov.br/
} 


\section{$=$ TRAMA $=$}

um sentido de vida, de uma visão de mundo - é a compreensão das partes que vai levar à totalidade efetiva; e transcendência, quando o momento da mediação extrapola-se e o conhecimento adquirido, através da ação mental, projeta generalizações, estendendo-se no tempo e no espaço - é a capacidade de síntese que adquire o indivíduo para toda vida, levando definitivamente à modificabilidade (FEUERSTEIN, 1991 APUD SILVA ET AL, 2011, p. 26, grifo nosso).

Feuerstein (1991) defende aqui o princípio da modificabilidade estrutural cognitiva e a capacidade que todo e qualquer ser humano tem de elevar o seu nível de desenvolvimento intelectual a partir da influência do mediador. Nesse processo colaborativo e facilitador da aprendizagem, os estudantes embarcam em novas descobertas. Por isso, enfatizamos que o professor, ao atuar como mediador, deve estar ciente do nível de dificuldades dos seus alunos para, então, buscar desenvolver neles as habilidades ainda não consolidadas, fazendo com que aos poucos, tomem consciência da sua trajetória de aprendizagem.

Caminhando nessa direção, a experiência da leitura de deleite proporcionada na escola, através dos Ciclos de Leitura MAISPAIC, trabalha o texto literário de forma prazerosa e aparentemente descompromissada, possibilitando aos alunos transitar por diversos espaços, sentimentos e emoções, que ajudam a refletir sobre os fatos da vida cotidiana e a interligar os sentidos despertados pela obra lida à sua visão de mundo. Contribuindo, assim, para a própria formação humana e intelectual dos alunos, e para a tomada de consciência das suas aprendizagens.

Ao analisarmos as orientações metodológicas nos referenciais do Programa MAISPAIC para o Eixo de Literatura e Formação do Leitor, aprofundamos o nosso olhar também para o Círculo de Cultura de Freire, entendido como uma metodologia que dialoga com o princípio da modificabilidade, de Feuerstein. Freire (2011) aponta para o contínuo processo de feitura do ser humano, visto como alguém inacabado que, ao ser envolvido nas condições de aprendizagem crítica, transforma sua visão de mundo, saindo da condição do saber ingênuo para a curiosidade epistemológica, entendida como a inquietação indagadora que nos move e nos conscientiza sobre os reais problemas do mundo. Freire (1987, p. 11) acredita na necessária superação da ingenuidade para o exercício da criticidade:

\footnotetext{
O círculo de cultura - no método Paulo Freire - revive a vida em profundidade crítica. A consciência emerge do mundo vivido, objetiva-o, problematiza-o, compreende-o como projeto humano. Em diálogo circular, intersubjetivando-se mais e mais, vai assumindo, criticamente, o dinamismo de sua subjetividade criadora. Todos juntos, em círculo, e em colaboração, reelaboram o mundo e, ao reconstruí-lo, apercebem-se de que, embora construído também por eles, esse mundo não é verdadeiramente para eles. Humanizado por eles, esse mundo não os humaniza. As mãos que o fazem, não são as que o dominam. Destinado a liberá-los como sujeitos, escraviza-os como objetos.
}

Assim, o Círculo de Cultura é tomado pelo Ciclo de Leitura MAISPAIC como um espaço democrático de encontros, reencontros e partilha de experiências de leitura literária favoráveis à promoção do livro, às leituras de enlevo e ao compartilhamento dos sentidos do texto para cada leitor. Esse diálogo é mediado pelo professor, que instiga o grupo ao exercício da compreensão textual e à mobilização dos conhecimentos prévios, ajudando a estabelecer relações entre o texto lido e os saberes de experiência dos alunos, num exercício contínuo de desenvolvimento da metacognição.

O Ciclo de Leitura, ao fundamentar-se no ideal do Círculo de Cultura, retoma alguns elementos tidos como essenciais para a concretização dessa metodologia: valoriza a opinião das crianças e jovens, abrindo espaço para exposição de seus posicionamentos e 


\section{$=$ TRAMA $=$}

questionamentos; coloca como função do professor-mediador o planejamento dos momentos de partilha literária, criando possibilidades de diálogos e questionamentos a respeito da obra ou trecho do livro lido pelos alunos; traz como ideal pretendido a ampliação do campo de experiências dos alunos, considerando o interesse literário dos estudantes para, a partir dali, possibilitar-Ihes o contato com outras obras.

Acrescenta-se ainda a ênfase dada à leitura literária feita pelo professor em voz alta e com o livro na mão, que promove o incentivo ao ato de ler e encontra ressonância na Pedagogia do exemplo. Freire (2011) enfatiza a importância do professor, ao trabalhar no quadro da rigorosidade do pensar certo, sabendo que as palavras a que falta a corporeidade do exemplo, pouco ou quase nada valem. Assim, o aluno, ao perceber o professor como um leitor ativo, pode também tornar-se um leitor protagonista.

\section{CICLO DE LEITURA MAISPAIC: DA FORMAÇÃO DO PROFESSOR AO CONTEXTO DA SALA DE AULA}

A produção desse artigo parte do desejo de compartilhar as experiências de acompanhamento junto aos professores durante as ações de formação do Programa MAISPAIC no Eixo de Literatura e Formação do Leitor, enquanto atuava na função de técnica da Crede 16 (Coordenadoria Regional de Desenvolvimento da Educação), órgão pertencente à Seduc-CE (Secretaria de Educação do Estado do Ceará), entre os períodos de 2016 e 2018, dando assistência pedagógica a sete municípios da região centro-sul do Estado do Ceará.

Desta forma, as análises ora apresentadas são resultantes de um estudo voltado para os materiais orientadores do Eixo de Literatura e Formação do leitor, denominados de agendas/guias, cuja estrutura organizacional é constituída de fundamentos teóricos e de sugestões de atividades para facilitar a atuação dos professores como mediadores de leitura na escola. Dentre as etapas que estruturam a vivência dos Ciclos de Leitura estão: o momento da predição do texto, a partir do título; a apresentação do livro, autor, obra, ilustrador e editora; a leitura exemplar feita em voz alta pelo professor e a realização do Círculo de Cultura, momentos dialógicos de troca de experiências entre os alunos, mediados pelo professor.

Partindo dessa Proposta metodológica, compreendemos que os Ciclos de leitura ou Alforje de histórias, como também é denominado para as turmas de $3^{\circ}$ ao $5^{\circ}$ anos, devem efetivar-se no cotidiano escolar como parte integrante da rotina pedagógica dos professores, de modo que estes possam promover jornadas literárias semanais ou quinzenais, a serem enriquecidas pelas interações no Círculo de Cultura. Ao analisarmos o documento orientador do Ciclos de leitura, consideramos que a sua estrutura, composta de perguntas e respostas, dão clareza do propósito de sua implementação no cotidiano escolar, direcionando os professores para um trabalho inicial de sensibilização dos alunos para a leitura literária na escola, evidenciando quatro etapas como essenciais:

Existem quatro etapas de reunião. A primeira é de sensibilização para a leitura e escolha do livro a ser lido. A segunda etapa, consiste numa série de encontros de acompanhamento da leitura em que o professor-mediador estimula os leitoresprotagonistas. A terceira consiste no planejamento e ensaios com o objetivo de definir o conteúdo da quarta etapa, que é o evento de encerramento de um ciclo de leitura (CEARÁ, 2018, p. 6 - Grifo do autor).

O processo formativo do Programa no Eixo do Leitor funciona como um estímulo ao professor para aperfeiçoamento de sua prática, visto que, muitos docentes, por não terem adquirido em sua formação acadêmica conhecimentos teóricos e práticos para o trabalho com a leitura literária em sala de aula, sentem-se inseguros diante do desafio de engajar-se no ciclo 


\section{$=$ TRAMA $=$}

de leitura. Por isso, uma agenda/guia contendo orientações teórico-metodológicas é direcionada aos professores, para facilitar a condução dos Ciclos de Leitura.

As propostas organizam-se em torno de um tema, a partir do qual é apresentada uma sequência didática dividida em etapas, contendo o objetivo da aula e as propostas para realização da atividade. As sugestões de obras literárias a serem partilhadas no momento de realização dos Ciclos são variadas, podendo ser utilizados o acervo literário do Programa MAISPAIC, os livros do PNBE (Programa Nacional Biblioteca na escola), acervos da biblioteca da escola, ou de uso pessoal do professor, bem como outras obras propostas durante cada encontro de formação.

Durante o percurso de acompanhamento às formações regionais e municipais, vivenciamos, junto aos formadores e aos professores, leituras que fundamentavam a proposta teórica dos Ciclos e ampliavam a nossa visão em relação à abordagem fruitiva do texto literário em sala de aula. Desses momentos formativos, apresentamos como experiência exitosa a socialização do livro "Eu conto contigo!", idealizada pelo eixo de Literatura e Formação do Leitor, com o objetivo de contribuir com os professores na dinamização dos acervos literários de uma das coleções do MAISPAIC, "Prosa Poesia", lançada no ano de 2016 para atender a Educação e infantil e os anos iniciais do fundamental. Vejamos sobre que aspectos foram construídas as propostas didáticas contidas no livro:

Na gênese do trabalho, nos debruçamos cuidadosamente sobre a nova coleção de livros do PAIC, e elaboramos propostas singularizadas para cada um deles, porém não se trata de um material exclusivo para esses títulos, você poderá aproveitá-lo em diversas propostas de mediação de leitura, continuamente nos esforçamos para contribuir com sua condição autoral, de forma que as propostas permitissem que, além de ampliar e /ou complementar cada sugestão, você também possa pensa-la para outros títulos deste e de outros acervos, fazendo as devidas adequações (CEARÁ, 2016, p. 7).

Nas instruções aos professores para o trabalho com as obras da coleção do PAIC Prosa e Poesia, apresentadas no livro "Eu conto contigo!", encontram-se delineadas propostas para o professor-mediador atuar no Ciclo de Leitura, em três estágios: Contexto Literário, momento de apresentação e convite à apreciação da obra; Propostas de oralização, com dicas potencializadoras para a narração do texto pelo professor; e Campos de Experiências, momentos de trocas de experiências e ampliação de conhecimentos, podendo anteceder ou suceder à leitura oralizada do texto.

A inserção do Eixo do Leitor na formação do professor, as orientações da agenda-guia, as sugestões do livro "Eu conto contigo!", e a disponibilização de acervos literários das Coleções MAISPAIC para todas as escolas municipais, constituem-se como estímulos à presença semanal da leitura literária na sala de aula. Essas ações dão o suporte necessário aos professores para a incorporação dessa metodologia à rotina escolar. Vejamos, então, as orientações trazidas na cartilha do "Alforje de histórias", para a realização do Ciclo nas turmas de terceiro ao quinto ano do ensino fundamental I:

Sistematizados na rotina semanal, os encontros do Alforje de histórias deverão acontecer no mínimo uma vez por semana, com duração entre trinta e cinquenta minutos. Cada encontro deverá ser planejado dentro de uma estrutura composta por dois momentos distintos e indissociáveis: partilha oral de um texto literário e organização de um círculo de cultura. [...] Esses encontros sistematizados preconizam a partilha oral do texto literário e dentro dos pressupostos do ensino da língua são afastados de qualquer exploração didática da obra. [...] as atividades sistematizadas para a prática da leitura literária foram desenhadas de 


\section{$=$ TRAMA $=$}

forma que a literatura sempre se apresente viva e prazerosa, como objeto de fruição e deleite (SEDUC-CE, 2016, p. 4).

Das relações tecidas entre as orientações teórico-metodológicas e a prática desenvolvida pelos professores em sala de aula, na vivência do Ciclo de leitura, podemos afirmar que muitos docentes, em cada um dos sete municípios que realizamos acompanhamento, vêm se dispondo ao desafio frente ao papel de mediador dos Ciclos de Leitura. Dentre as atividades realizadas, presenciamos festivais de talentos, em que o município envolve todas as escolas em atividades artísticas, para compartilhamento das obras literárias trabalhadas com os alunos ao longo do ano; momento em que os estudantes são chamados a exercer seu protagonismo estudantil, na apresentação criativa de uma das obras literárias lidas.

As ações diferem de um município para o outro, e cada escola encontra caminhos e possibilidades para que a vivência do Ciclo seja um momento motivador, instigante e desperte nos alunos o gosto pela leitura através de experiências fruitivas com o texto literário. Das demais experiências que pudemos presenciar, citamos o piquenique literário, realizado em praça pública, com o intuito de envolver os alunos na partilha de obras lidas e despertar o interesse dos transeuntes através da partilha oral de textos pelos alunos, teatralização das obras, realização de chás literários e saraus de poesias. Entendemos esses eventos de culminância como uma extensão do trabalho desenvolvido pelo professor-mediador conforme as suas possibilidades e certamente exercem um impacto positivo na formação de leitores protagonistas.

\section{CONSIDERAÇÕES FINAIS}

Consideramos os Ciclos de Leitura, como uma experiência de mediação da aprendizagem, que têm impulsionado os docentes a abordarem novas estratégias para o trabalho de compreensão textual e influenciado os alunos no aprendizado do deleite literário para desenvolvimento da metacognição e da sua formação como leitores protagonistas. O que foi favorecido pela produção e disponibilização de livros de literatura às escolas, apresentando temáticas próximas da realidade contextual dos alunos. As coleções MAISPAIC Prosa e Poesia, conforme depoimento dos professores, facilitam a vivência do ciclo de leitura, exatamente por tornar o livro acessível aos alunos.

Enfatizamos a importância da vivência da leitura literária na escola, considerando o seu valor para a formação humana no despertar da consciência crítica e da autonomia dos estudantes. Percebemos também que, até o presente momento, a abordagem do texto literário, em muitas escolas, não consegue ainda atrair os alunos para o universo da leitura. O trabalho com o texto, muitas vezes, serve como subterfúgio para exploração da gramática, uso de fichas de leitura, entre outras atividades enfadonhas, que nem de longe contribuem para a formação do leitor.

Pensando nisso é que buscamos nos apropriar de conhecimentos relativos à Experiência da Aprendizagem Mediada, na tentativa de encontrar alternativas metodológicas para o trabalho com a leitura literária na escola, tendo em vista a formação do leitor protagonista e a progressão intelectual dos alunos. Analisamos os Ciclos de Leitura MAISPAIC, nas experiências de compartilhamento da leitura literária, no encontro com o Círculo de Cultura, como uma entre várias possibilidades de tornar a EAM contínua e significativa para os estudantes no cotidiano escolar. Entendemos que a proposta apresenta um novo formato para o trabalho com a literatura na escola, tendo como finalidade última a transformação do leitor principiante em leitor ativo. 


\section{$=$ TRAMA $=$}

Destacamos, por fim, a importância da formação dos professores no eixo de Literatura e Formação do Leitor, como fator impulsionador para a realização dos Ciclos de Leitura na escola, uma vez que esta formação contribui eficazmente para a modificabilidade estrutural dos professores, no sentido de proporcionar-Ihes a aquisição de novas habilidades para atuação como mediadores de leitura. Para que, assim, possam também promover a modificabilidade da estrutura cognitiva dos estudantes, retirando-os da posição de leitores iniciantes e formando leitores protagonistas.

\section{REFERÊNCIAS}

BAKHTIN, Mikhail. Estética da Criação Verbal. 2. ed. São Paulo: Martins Fontes, 1997.

2016. Os gêneros do discurso. Organização, tradução e notas de Paulo Bezerra. São Paulo: Editora 34,

CEARÁ, Secretaria de Educação Básica. Cartilha Alforge de histórias. Encontros literários que sopram bons ventos na escola. Uma atividade destinada às turmas de $3^{\circ}$ ao $5^{\circ}$ ano do Ensino Fundamental. Fortaleza: SEDUC-CE, 2016.

CEARÁ, Secretaria de Educação Básica. Eu conto contigo! Dinamização do acervo PAIC Prosa e Poesia. .Eixo de Literatura e Formação do Leitor. Fortaleza: SEDUC-CE, 2016.

CEARÁ, Secretaria de Educação Básica. Guia de Orientações para o acompanhamento das CREDES aos municípios e escolas. Fortaleza: SEDUC-CE, 2017.

CEARÁ, Secretaria de Educação Básica. Orientações para o acompanhamento das CREDES aos municípios e escolas. Fortaleza: SEDUC-CE, 2018.

COSSON, Rildo. Letramento Literário: teoria e prática. 2. ed. São Paulo: Contexto, 2014.

FEUERSTEIN, Reuven. Mediated learning experience: teoretical, psychosocial and learning implications.

Tradução para fins didáticos. Londres: Freund Publishin House LTD,1991.

FLAVELL, J. H. Metacognition and cognitive monitoring: a new area of cognitive-developmental

inquiry. American Psychologist, v. 34, p. 906-911, 1979.

FREIRE, Paulo. Pedagogia do Oprimido. 17. ed. São Paulo: Paz e Terra, 1987.

Pedagogia da Autonomia: saberes necessários à prática educativa. São Paulo: Paz e Terra, 2011.

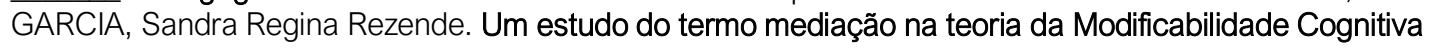
EstruturaL de Feuerstein à luz da abordagem sócio-histórica de Vygotsky. Dissertação de Mestrado em Psicologia. Universidade São Marcos, São Paulo, 2004.

NEVES, Dulce Amélia de Brito. Meta-aprendizagem e Ciência da Informação: uma reflexão sobre o ato de aprender a aprender. Perspectivas em Ciência da Informação, vol. 12, n.3 Belo Horizonte Set./Dec. 2007 SILVA, Regina Claudia de Oliveira da; REIS, Francisca das Chagas Soares; NASCIMENTO, Vilmar Andrade do. O contador-mediador de Histórias. Fortaleza: Expressão Gráfica e Editora, 2011.

SOLÉ, Isabel. Estratégias de leitura. 6. ed. Porto Alegre: Artmed, 1998.

VYGOTSKY. Lev Semyonovich. A Formação Social da Mente. 4. ed. São Paulo: Ed. Fontes, 1991.

ZILBERMAN, Regina. A literatura infantil na escola. São Paulo. 8. ed. Global editora. 1994.

Recebido em 29-11-2019.

Aceito em 15-02-2020. 